\title{
Lyophilisate Dosing Unit
}

National Cancer Institute

\section{Source}

National Cancer Institute. Lyophilisate Dosing Unit. NCI Thesaurus. Code C149631.

A unit of presentation used to represent the quantity of product that is found in a single discrete entity where the pharmaceutical dose form is a type of lyophilisate. 